\title{
Homo HibERNICUS: MYTH, ETHNOGRAPHY AND NATIONALISM IN ROBERT \\ FLAHERTY'S MAN OF ARAN
}

James Carney

\begin{abstract}
Why did Robert Flaherty's Man of Aran resonate so strongly with the cultural milieu of 1930s Ireland? I argue that Flaherty's documentary, despite its mimetic intentions, has, in fact, the semiotic form of a foundation myth. A consequence of this, I suggest, was that Flaherty's film would have been instrumental in activating nationalist narratives of self-determination and colonial oppression that were then current in the nascent Irish State. Additionally, a subsidiary (and related) goal of my discussion is to show, by way of Flaherty's film, that the documentary form is no less structured by normative cultural codes than its fictional counterparts.
\end{abstract}

\section{INTRODUCTION}

Though deserving of its reputation as a masterpiece of ethnographic film-making, Robert Flaherty's 1934 Man of Aran reproduces - and indeed initiates - several of the characteristic problems of the anthropological documentary. Primary among these is the question of veracity, or to what extent the filmic artefact subordinates the accurate representation of its subject matter to generic conventions. The problem here, as David MacDougall notes, is that the ethnographic film has its origins "in the essentially European invention of documentary cinema, which embodies in its stylistic conventions still earlier European inventions and assumptions about behaviour and discourse' (1992: 91). As might well be expected, this mismatch between the mode and the object of representation creates severe challenges for the ethnographically orientated film-maker, who is forced to choose between satisfying audience expectations and honouring the anthropological record. Obviously, different cinematographers will choose to resolve this dilemma in different ways; but there can be little doubt that negotiating a path between the competing imperatives of artistry and accuracy represents perhaps the central difficulty of the ethnographic documentary.

My purpose in raising these issues in the context of Man of Aran is not so much to chart how Flaherty resolves these problematic issues - a topic on which Hugh Gray (1950), George C. Stoney (1978), Solon T. Kimball (1979), John C. Messenger (2001), and Dara O'Curraidhin (2010) have already produced notable commentaries. Instead, I will suggest that the uncritical valorisation of ethnographic fidelity often forestalls the interpretive 
imperative of analysing the ethnographic film as a cultural document in its own right. To be sure, there are compelling reasons why ethical concerns should trump aesthetic ones when evaluating filmic representations of communities who are in some way vulnerable or marginalised. However, this preoccupation with the mimetic dimension of ethnographic cinema is frequently pursued at the expense of a much-needed reflection on the deep structures of the filmic artefacts in question. The problem with this, as Keyan Tomaselli notes, is that it leads to 'the film being read in terms of a single criterion - the ethnographic - thus missing other levels of encoding [...] in which the key to interpretation exists' (1992: 214). To the extent that this is true, it thus follows that any comprehensive understanding of the ethnographic documentary must exhibit a semiotic consciousness that is at least the equal of that deployed in the analysis of ostensibly fictional genres.

In the present essay, I hope to make a concrete contribution to this critical agenda by showing that Man of Aran, beneath its ethnographic colouring, has the semiotic form of a foundation myth. I am well aware that this may seem an extravagant claim, especially when the representative ambitions of documentary and myth are, in so many other ways, the polar opposites of one another. Nevertheless, my analysis will show that Man of Aran implicitly encodes a process of cosmological creation, where a deficient cosmology is transformed into a sufficient one through the actions of man. In detail, this will involve charting how an initial opposition between two elements - air and water-is mediated by the Islanders' creation of earth and fire from the bounty of the sea. What this will show is that the narrative trajectory of Flaherty's film cannot be reduced to any simple formulation like 'man versus nature' (Pettitt 2000: 29) but instead details the effective creation of a metaphysical dispensation.

This idea leads naturally to the second point I wish to address here, which concerns the domestic response to the film in Ireland. Like all constellations of represented value, the metaphysical charter announced by Man of Aran has a strongly normative dimension. Indeed, I will argue that it is precisely this normative dimension that made the film appropriate to the socio-historical circumstances of the nascent Irish State. Though Man of Aran performed well internationally, its reception in Ireland was particularly positive, with several major figures from Irish political and cultural life lauding the film as being 
true to the spiritual values of insular Irish identity. I will account for these and subsequent appreciations of Man of Aran as an 'authentic' expression of the Irish national character by reverting to its implicit delineation of a creation myth. Specifically, I will suggest that certain details of the creative process depicted in the film made it particularly amenable to nationalist appropriation. In essence, this will involve showing how the film codes reality in a way that would necessarily have activated the 'official' narrative of Ireland's emergence as a political actor on the part of its audience. Thus, I will show how Man of Aran, by virtue of its concealed cosmological ambitions, succeeded-however unwittingly - in affirming a broader set of cultural codes that were instrumental in shaping the early Irish State.

When considered in concert, I expect that both of these claims will go some distance towards addressing my main research agenda-namely, the desire to explore in greater depth the types of semiotic coding deployed in the filmic documentary. Naturally, my conclusions will be informed to some degree by the idiosyncrasy of my subject matter; but I nevertheless hope that they will still retain a value that goes beyond the immediacy of their motivating material.

\section{1-MAN OF ARAN AND THE MYTHIC IMPULSE}

'Myths,' writes Claude Lévi-Strauss, 'have one purpose only: to come to terms with history, and, on the level of the system, to re-establish a state of equilibrium capable of acting as a shock absorber for real life events' (1981: 607). Implicit in this formulation is the idea of myth as an attempt to neutralise history, in that the central goal of the mythic consciousness is to reduce the complexity of the present by subordinating it to a pattern established in primordial time. This much is also suggested by Mircea Eliade when he argues that, 'being real and sacred, the myth becomes exemplary, and consequently repeatable, for it serves as a model, and by the same token as a justification, for all human actions' (1960: 23). Finally, Bronislaw Malinowski asserts that 'the function of myth $[\ldots]$ is to strengthen tradition and endow it with a greater value and prestige by tracing it back to a higher, better, more supernatural reality of initial events' (1984: 146). Thus, whatever definition of myth one chooses to adopt, the general point seems to 
remain the same: myth responds to the anxiety of historical change by identifying permanence in contingency.

In the present section, my intention is to show how this mythic compulsion to coordinate a fallen present (implied, if not depicted, as industrial modernity) with a more elevated reality functions as the central thematic impulse of Man of Aran. Specifically, I hope to demonstrate that Flaherty's film implicitly encodes a process of world creation, in which a dualistic ontology consisting of two elements - air and water - is transformed, through the apparatus of culture, into a traditional quadripartite ontology that contains fire and earth. As hardly needs stating, I will identify the Aran Islanders as the principal agents of this transformation; and in doing so, highlight their promethean role in not just inhabiting an ontological dispensation, but actively shaping it - a result that will be of obvious value later, when it comes to investigating the exemplary force of Man of Aran in Irish political culture. Moreover, in performing this analysis, I will not just delineate the tacit material ontology in Man of Aran; I will also engage with the set of values that this ontology supports. That is, I will explore how each of the four substances nominates an existential absolute that defines the character of the world the Islanders inhabit. The result of this will be a sustained treatment of how Man of Aran succeeds in conveying a mythic vision of the world by cross-fertilizing an archaic ontology with normative prescriptions.

To begin, it is worth recounting the opening sequence of Flaherty's documentary, which, as we will see, plays a crucial role in setting up the basic structure of the film. Here, the camera cuts between two sub-sequences: one centring on Michael, the son of Colman 'Tiger' King, the eponymous Man of Aran; and the other on Tiger's wife, Maggie. In Michael's sequence, we see him performing a comic version of the activity that animates almost all human activity in the film - namely, extracting an item of value from the sea at risk of personal danger. In this case, the item of value is fishing bait in the form of a crab; the personal danger is signalled by the crab's nipping of Michael's fingers. Maggie, for her part, firmly situated in a highly gendered domestic role, where her status as a telluric materfamilias is advertised by homely close-ups of the sleeping babe, the roosting hens and the placid livestock that make up the mise-en-scène of the 
cottage. (See Cheryl Temple-Herr [2003] for a more involved discussion of gender in the film than I am able to offer here.)

It is significant to note, however, that behind the overplayed sentimentality of both sequences, a signifying economy is at work that announces, in embryonic form, the central narrative arc of the film. In the first instance, Michael's capture of the crab is diachronically linked to the later scene where, when using the crab to catch wrasse from the cliffs, he encounters the basking shark. In view of the fact that, as we subsequently learn, the basking shark's liver provides oil for the Islanders' fires, Michael's actions thus anticipate the central value of ingenuity that allows for the transformation of nature into culture. This is further augmented by his placing the crab under his hat (signifying the essentially cognitive nature of his activities) and in the fact that, as Zoltán Kövecses (2000: 79-92) notes, cognition is itself is frequently represented using fire imagery. Maggie's sequence, by contrast, represents the logical endpoint to the actional programme initiated by Michael. Where Michael is motivated by the experience of lack (he desires to catch a fish), Maggie's situation offers a vision of plenitude. On the one hand, this can be seen in the opening frame of her sequence, which, significantly enough, features an actual fire. On the other, the various homely elements that make up the interior of the cottage all encode the value of fecundity - a characteristic that is conventionally associated with the earth. Thus, what the opening sequence delineates is the start and terminal points of a process of transformation, whereby one hostile element - water-is transformed into the two benign elements of fire and earth.

Nevertheless, two things are missing in this tableau. Firstly, there is the obvious fact that the fourth element of air receives no representation. Secondly, the details of the transformative process are left unspecified, to the extent that Michael's actions anticipate rather than enact the process in question. This situation is quickly resolved towards the end of Maggie's opening sequence, when the early gusts of the storm threaten to blow out the lamp in the cottage. Here, we have the figuring of the two missing elements. Clearly enough, the wind is coincident with air, thereby completing the implicit cosmology. Perhaps more importantly, however, the storm is occasion for the introduction of the notion of competence into the narrative. Specifically, where Michael's play encodes ingenuity in an inchoate form, the storm-prompted return of the fishermen from the sea 
represents its mature embodiment. To this extent, they will clearly be the vehicle that mediates between the two visions of lack and plenitude that inform the initiating subsequences of the film - and from this comes the basic narrative tension that sustains the documentary for its entire length.

With the basic conceptual infrastructure of the film now set up, Flaherty moves the action forward in the next introductory sequence, which explores the issue of competence in greater depth. Largely, this is represented by the successful - though still fraughtnegotiation of the hostile nature of water. This hostility is represented in a series of stages that proceed from the demonstration of agency to the depiction of active hostility on the part of the sea. That the sea has agency is evident from both the framing and the editing of film. In the former case, the hallmark frame of Man of Aran comes from a wide-angle, long-distance shot of a human agent being dwarfed by the natural elements; while in the latter, the camera repeatedly cuts between shots that detail the struggle of the human agent to escape from the sea and the inexorable progress of the waves towards the shore. On the back of these cinematographic staples, Flaherty succeeds in attributing an active hostility to the sea by detailing two failed invaginations. The first of these comes with a close-up of the punctured currach, where the sea has penetrated the skin that protects the fishermen from the element that immerses them. The second is the far more symbolically loaded abduction sequence, where Maggie is nearly dragged from the rocks by the advancing waves. Considering that Maggie has previously been set up as the inhabitant of an internal, domestic space - the cottage - what is being signalled by this metaphorical attempt at rape is the sea's ability to violate the protective cocoon of culture itself. Moreover, as we will see in the next section, this abduction sequence is of crucial import when it comes to documenting the socio-historical impact of the film; but as I will deal with this issue then, I will forego any further discussion of it for now. Here, the main point to note is that it is only by dint of near-herculean efforts that the Islanders succeed in preserving their cultural and familial integrity in the face of the sea (figure 1). 


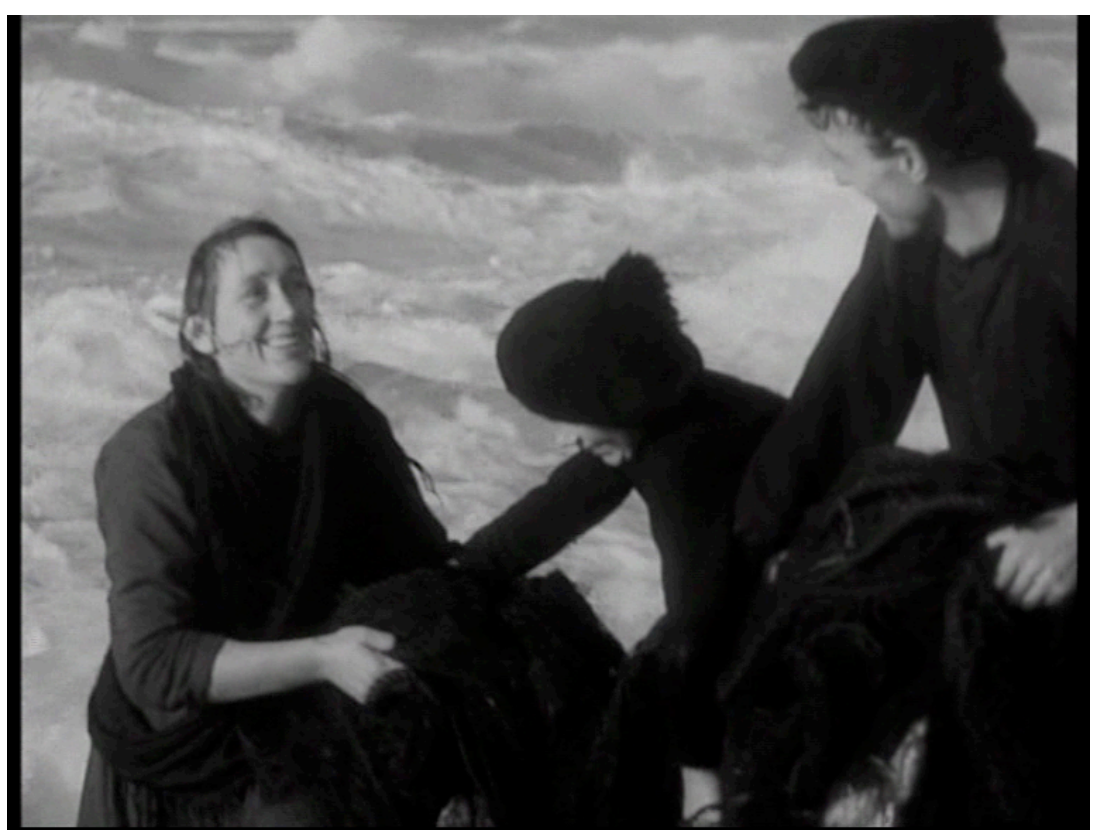

Figure 1: Familial Integrity

The next major sequence of Man of Aran comes with the first of two meditations on the creation of earth and fire. These meditations take up the extant germinal representations of both elements and amplify them into full-fledged expositions on their creation through cultural activity. Earth is the target of the first sequence, as is advertised plainly enough by the textual preface, which asserts - inaccurately, but with appropriate melodramathat "The land upon which Man of Aran depends for his subsistence - potatoes - has not even soil!" What immediately follows this is a series of cuts that juxtapose shots featuring only the denuded rocky landscape of the Island against shots featuring this landscape adjacent to the sea. The message is clear: the landscape on its own is insufficient; it needs to be adulterated by the sea if it is to become fecund. The last of these shots details precisely how this happens by panning to the cluster of cottages, thereby indicating that it is through cultural means that earth is generated from the sea. Subsequent to this, the agents of this generative activity are introduced, which consist of the fundamental unit of human regeneration-namely, the nuclear family (here consisting of Maggie, Tiger and the baby). Tellingly, one shot features Tiger, with a sledgehammer over his shoulder, occupying a position that vertically intersects with earth, sea and air (figure 2). As needs little explication, this Sovietesque show-casing of Homo faber as the 
mediator between the elements points towards the transformative agency of culture in redressing the deficiency in the cosmological order of the world.

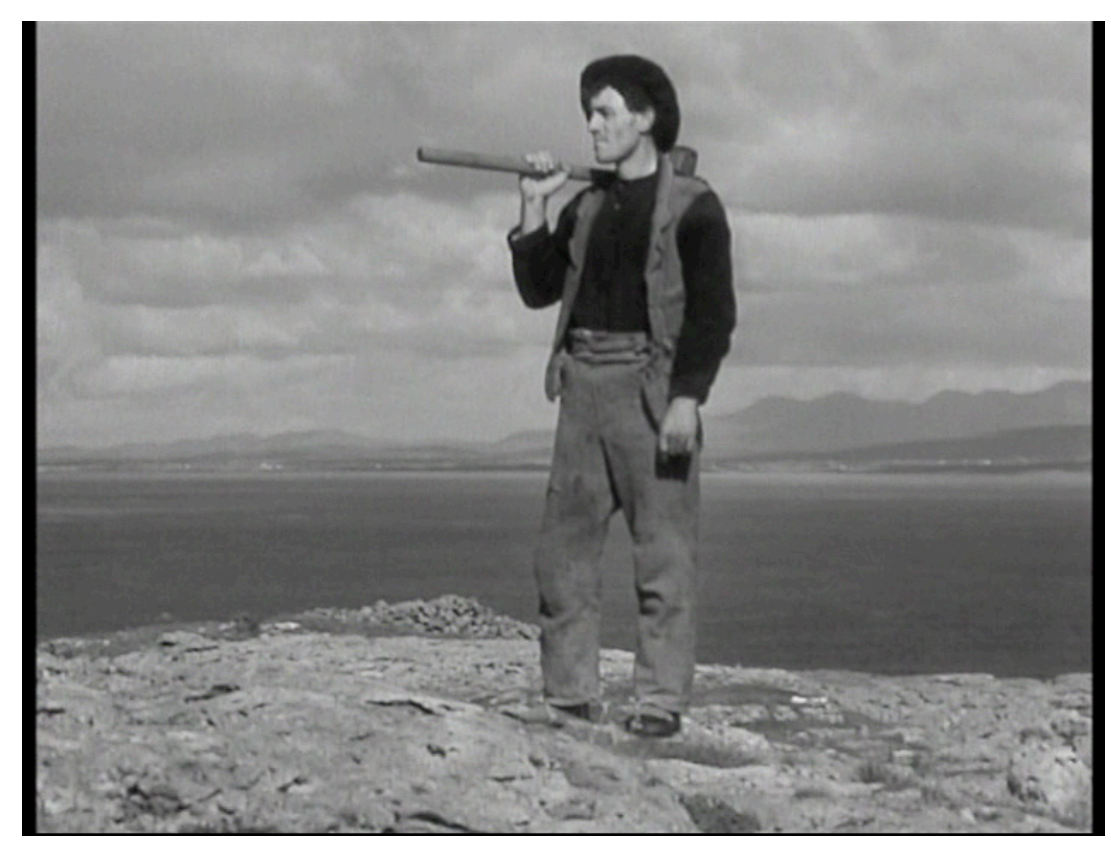

Figure 2: Homo Faber

What follows from this shot is a series of close-ups that further emphasise the presence of fecundity by featuring various farm animals and their young in a scene of bucolic reverie. This, in turn, segues into the conjoining of Tiger's and Maggie's actional sequences in a single shot, which pans from Maggie carrying a basket of seaweed to Tiger breaking rocks with the sledgehammer. Apart from the quasi-sexual coding at work here, the most important element is the seaweed, to the extent that it is metonymically linked to the sea. The subsequent shots all concentrate on this by reiterating the central trope of the film - namely, the retrieval of goods from the sea at risk of personal danger. As with Michael's opening sequence, the danger here is slight; but the struggles of the Islanders as they guide the seaweed-loaded horses across the lagoon makes evident that the adversity being challenged in this instance comes in the form of work. This is further emphasised by the final instalment of the meditation on the creation of earth, which sees Maggie, Michael and Patch Ruadh laboriously search rocky crevices for wind-blown soil. This soil is then added to the seaweed in a shot that 
harmoniously re-states the parallels between human and natural fertility by again panning from Maggie to Tiger as they create the basic conditions of reproduction (figure 3).

Thus, what emerges from all of this is the role of labour in generating a core substance of the world. This labour, however, is not the labour of the drudge; but instead, the labour of world creation-even if Flaherty would have us believe that Man of Aran could just as easily go without the customary rest on the seventh day.

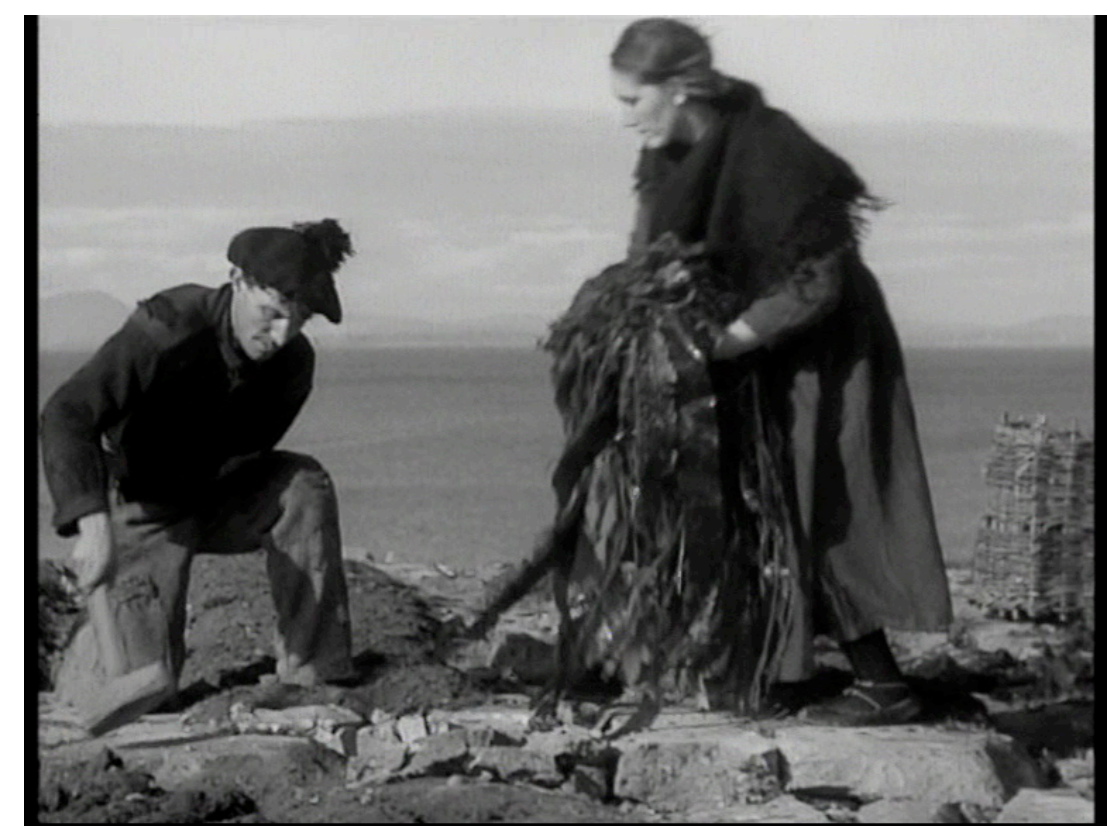

Figure 3: The Creation of Soil

This brings us to the second exposition of the film, which explores the creation of fire. Just as the creation of earth sequence is framed in terms of farming, this meditation is expressed through the vehicle of another fundamental human activity - that of hunting. However, where farming offers the prospect of sustained labour at low risk, hunting offers an inverted dispensation where high risk is paired with low labour investment. Thus, the creation of fire meditation replaces application with courage as the emphasised value. In terms of detail, this sequence begins with a response to the first invagination mentioned above, in that it shows Tiger repairing the hole in the currach featured in the introduction. Significantly, he caulks the hull using a smoking ember and a tarred cloth, and in doing so, uses two substances that coincide with or originate from fire. At the 
same time, a series of cross cuts show Michael reprising his actions in the opening sequence, in that he goes fishing with a hand-line using the captured crab as bait. However, Michael's activities only serve to counterpoint the development of Tiger's sequence, which, as we soon discover, is a prelude to a shark hunt. The forbidding seriousness of this activity is made particularly evident in the shot that frames figure 4, where the impressive array of harpoons and the like could not contrast more with the ludic nature of Michael's hand-line.

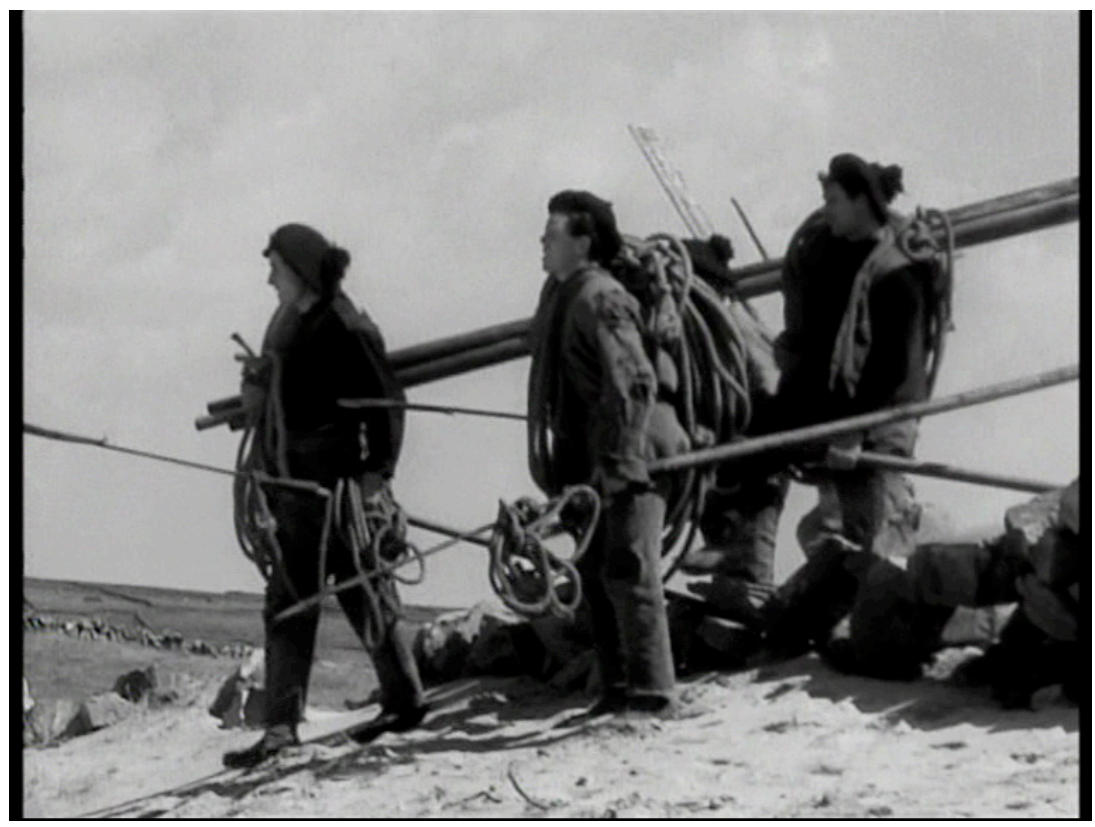

Figure 4: Assault on the Sea

Nevertheless, where the two sequences meet (as complementary sequences inevitably do in Man of Aran) is when Michael encounters the basking shark. In a neat reversal of the short shot featuring the expiring wrasse that he has caught, Michael is equivalently displaced from his own element by the sight of the shark's gaping maw (figure 5). On the symbolic plane, this evocation of negative space suggests that the sea, as well being able to penetrate, is also penetratable. Thus, just as the sea has previously enacted the male prerogative of invagination, here we see it as being placed in the female role of propensity to invagination. As with the creation of earth sequence, this distribution of roles is evocative of a sexual dynamics, where the penetration of the sea corresponds to a 
generative act. Nevertheless, it is equally clear that the monstrous character of the basking shark points to the danger of the sea as a potentially engulfing medium - a characteristic that immediately brings to mind a host of cultural stereotypes that identify femininity as devouring.

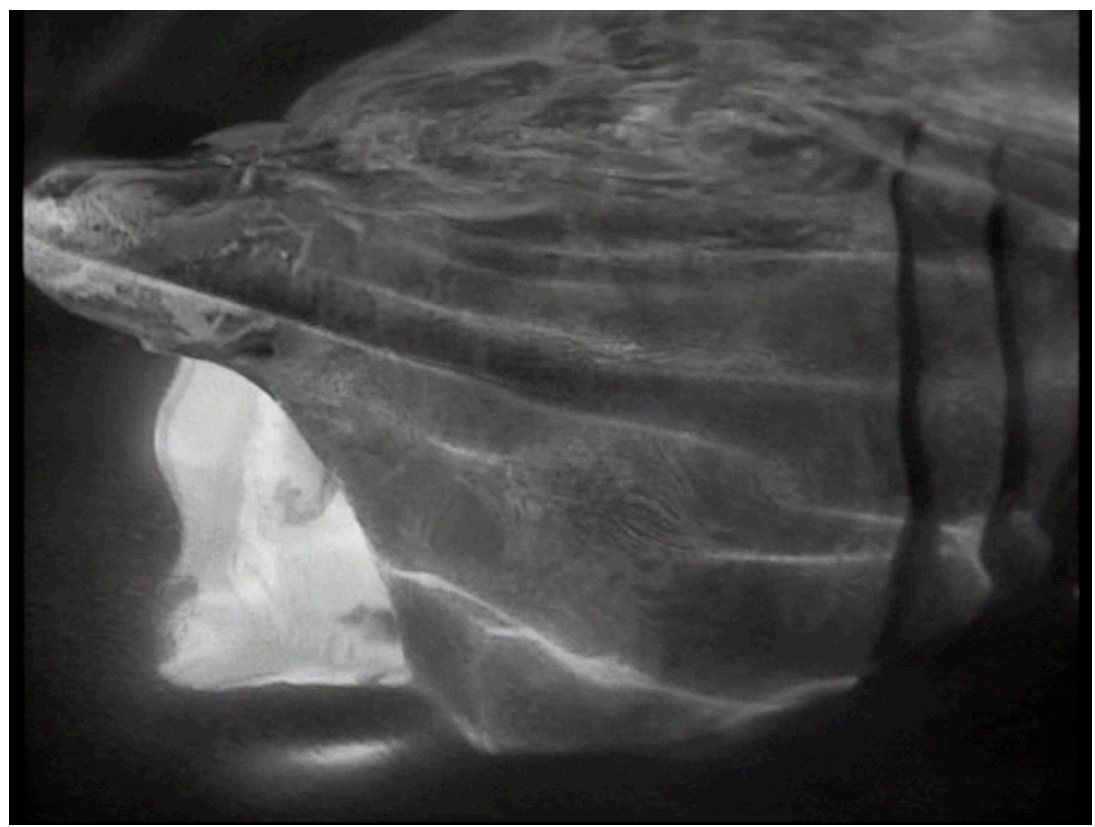

Figure 5: The Engulfing Nature of Water

From here, the action moves to the enterprise of catching the shark. Three points of note emerge from this. Firstly, the struggle of the fishermen against the shark is interposed with shots of Maggie and Michael as they watch from the shore. Again, the emphasis here falls on the structural parallel between the family as a mechanism of human reproduction and culture (figured by way of the shark hunt) as an equivalent mechanism for transforming the affordances of the nature into the means of future survival. Secondly, it is notable that it is only on the second attempt that the fishermen succeed in harpooning the shark. As a form of invagination, this deferred success recalls the earlier abduction sequence, where Maggie is nearly carried off by the waves. However, where the sea fails in this, the fishermen - and Tiger in particular - succeed in their second attempt to extract value from the sea. Thus, there is a clear sense in which the shark hunt constitutes a form of revenge for the fishermen. The final issue of 
importance concerns another parallel - in this case, that between the previous meditation on the creation of earth and the current one, which details the securing of fire. Specifically, it is evident that the beating of the basking shark's tail-fin against the currach after it has been harpooned echoes, in precise detail, the measured strokes of Tiger's sledgehammer when, in the creation of earth sequence, he creates seed drills for the family farm. Thus, at the structural level, the creation of earth and fire are posited as being equivalent activities, in that they each involve two phallic tools - the sledgehammer and the harpoon - being combined with two appropriate cognitive dispositions - application and courage - to extract value from water.

The final instalment of the meditation on fire comes with the rendering of the shark's liver for oil. In this scenario, the principal agents are Maggie and Michael. In both cases, each character reprises the elemental association that has previously been established. Starting with Michael, his previous association with fire is amplified by his role as the bearer of the ember that lights the turf fire used to boil the shark's liver (figure 6). Similarly, Maggie's advertised affinity with the earth can be detected in her role as both the carrier of the turf that fuels the fire and the stirrer of the pot in which the liver is boiled. As A.J. Greimas notes, 'the pot [...] may be considered a utopic space, a place of the principal transformations from raw to cooked' (1983: 5). Here, it is evident that the earth, as an enclosing space that allows for the germination of seeds, is being coordinated with the pot as the incubator of oil (and hence fire), as well as the uterine space of Maggie herself as the bearer of future generations. (For a sustained meditation on the symbolic parallels between cooking and childbirth, the reader is referred to Lévi-Strauss [1969: 334-42].) Correspondingly, it is possible to claim that the sequence in which the shark's liver is rendered provides the final iteration of the cultural and natural processes that transform the deficient elements of earth and fire into sufficient ones. 


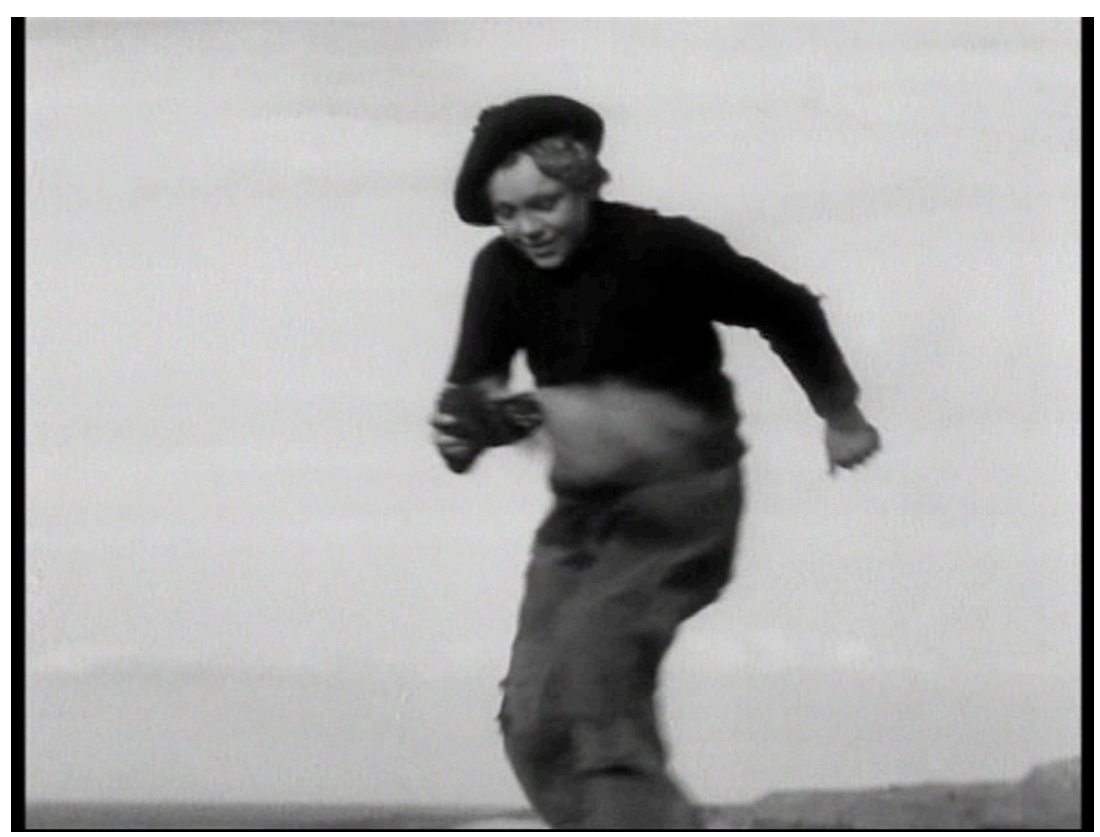

Figure 6: Prometheus as a Boy

Not unexpectedly, the last sequence of the film deals with the element of air. As a part of the given cosmological dispensation, air offers far less immediate symbolic traction than the elements of fire and earth; but its treatment nevertheless offers some points of note. In the first instance, just as the introductory sequences feature air (in the form of the wind) penetrating into the cultural space of the cottage, the cataclysmic storm of the closing sequence is prefigured in the enclosed space of the pot. Specifically, as Maggie stirs the shark's liver in the cauldron, the boiling froth of the mixture foreshadows the foam of the wind-driven sea (figure 7). From this point on, the film oscillates between shots featuring the interior of the cottage and shots depicting the storm in all its elemental fury. Significantly, in an echo of the introductory sequence, the storm threatens to blow out a lamp - though this lamp, as a scallop shell filled with oil, combines the elements of fire and water, and can correspondingly be considered an icon of cultural achievement. To this extent, the storm is not just a meteorological event, but can instead be construed as a threat to the entire cultural infrastructure of the Islanders. This point is taken up and amplified for the duration of the sequence, where, in a dramatic crescendo to the action, the fishermen barely escape with their lives as the sea smashes the currach against the rocks, with the frantic audience of Maggie and Michael looking on from the shore. The 
film then brings the action to a conclusion, with successive close ups of Tiger and Michael, the present and future men of Aran, forming the last symbolic instalment of the narrative.

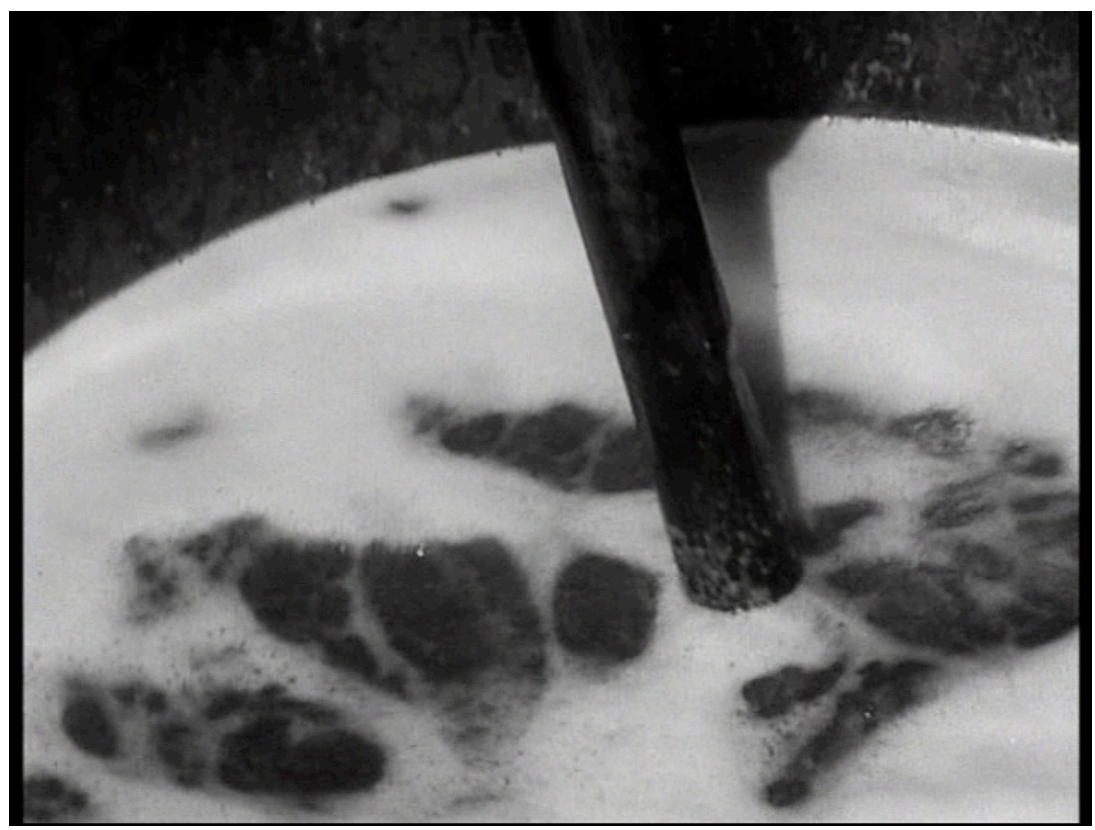

Figure 7: Brewing up a Storm

With the basic symbolic elements at work in Man of Aran now at least gestured towards, it is time to move on to a discussion of their significance. In practice, this means interrogating each of the four elements of earth, fire, water and air for the values that they carry beyond their immediate ontological signification. To begin with, the preceding speculations will have made clear that the elements of fire and earth are coterminus with culture. Specifically, both elements are the product of manufacture, and both have particular actional programmes and cognitive dispositions associated with them. Moreover, both elements are temporally inflected, in that fire represents a cultural tool that helps negotiate the present (fire, by its nature, is transitory), while earth represents an attempt to gain purchase on the future (crops take time to germinate and grow). Thus, the combination of both elements serves to articulate the essential rationality of the Islanders: unlike animals, which attend only to the needs of the moment, the people of Aran seek to insure themselves against the future. Considered from this perspective, the creation of earth and fire in Man of Aran serves to represent all 
of the symbolic and material processes of culture that make the world habitable for rational human beings.

When it comes to the elements of water and air, the encoded meanings are a little less clear cut. Perhaps the best way to resolve this issue is to contrast both elements with the meaning attributed to fire and earth. When we do this, we quickly see that nature-or more accurately, non-culture-emerges as the implicit signification. As useful as this may be, however, it does not tell us a great deal; so more analysis is required to unpack what the term 'non-culture' might involve. Starting with water, we can begin by noting that the sea forms the necessary precondition of the Islanders' culture. All of their cultural goods are extracted from the sea, and their entire repertoire of behaviours is shaped by the processes that facilitate this extraction. In fact, we can go further and suggest that the sea constitutes a basic existential category in their day-to-day existence. When we recognise this, it becomes evident that the sea is symbolically equivalent to space in structuring the Islanders' lives. In the opening text, we are directly told as much when it is announced, “The Aran Islands lie off Western Ireland ... All three are small wastes of rock ... without trees ... without soil ... In winter storms they are almost smothered by the sea..." This statement immediately coordinates our anticipation of the action with their spatial position - a position that is obviously determined by the sea. Moreover, in the subsequent sequences, the sea is assigned an equivalent spatial role by operating as a literal and figurative point of orientation in all of the Islanders' activities. What emerges from this, then, is that the logical role played by space in structuring human action is transferred, in Man of Aran, to the sea. From this follows not alone the film's mimetic value as an evocation of a maritime culture, but also its aesthetic facility for refracting general truths about human undertakings through a set of local cultural circumstances.

The last element in need of interpretation in Man of Aran is perhaps the most mysterious - that of air. The first clue to deciphering its specific set of connotations comes from the previous analysis of water as a coded form of space. This naturally leads us to expect that air will have an association with time- which is exactly what emerges when we examine the function of air in the film. In particular, the two major actional (as opposed to meditative) sequences in the film are introduced by gusts of air (or 
representations of such) penetrating into the enclosed space of either the cottage or the pot. To this extent, air is the agent of change, and hence its temporal denotation. Nevertheless, it is important to recognise that the symbolic role of air in the film is not exhausted by this description. Specifically, a sequential appreciation of time as the mere unfolding of events eclipses an understanding of air in its quasi-supernatural role as the vehicle of fate. In this connection, it has often been noted that religion is entirely absent from Man of Aran, despite the fact, as John Messenger records, that the Islanders 'are extremely devout, [even if they] hold strong anti-clerical sentiments and maintain pagan beliefs' (2001: 361). Against the claim that religion is elided from the film, my reading here suggests that Man of Aran is religious to its core, even if it does not feature religion in an explicitly 'theological' sense. (I should note too that this claim concerning the absence of religion in the film - made by George C. Stoney, among others - is, in any event, factually untrue: at one point, Maggie audibly mutters the 'Ár n-Athar,' or the 'Our Father' in Irish. Given his unfamiliarity with the language, it is a moot point whether Flaherty was aware of this or not.) Throughout the film, the role played by air in initiating and shaping the mortal struggles of the Islanders offers a glimpse of a suprasensible reality manifests itself in an agentive way. Moreover, as Jan Gabriël Van der Watt (2000: 175-176) notes, one of the most pervasive motifs in religions the world over involves the pairing of spirit with wind in the notion of pneuma, or breath. Thus, there are good grounds for viewing the role of air in Man of Aran as not just a representation of time, but as the combination of time with divine agency to produce the category of destiny. As with the figuring of water as space, this representation of air allows the film to escape its immediate subject matter and engage with deep human intuitions concerning the unseen realities that shape all forms of action.

Now that roles and meanings of the four elements of earth, fire, air and water in Man of Aran have been explored, it is possible to move on to the next concern of the present essay. Up to this point, the analysis has focused mostly on the symbolic infrastructure of the film itself, with a view to demonstrating that Flaherty's narrative is at all points concerned with the mythic project of detailing how crucial features of the world came into being. Now, I will expand my focus and move on to a discussion of the film's reception. In doing this, I will use the preceding discussions to resolve a simple question: 
Why did Man of Aran resonate so strongly with the official culture of 1930s Ireland? As we will see, the answer to this question is not so straightforward as one might expect on its first consideration.

\section{2-The Nationalist SEMiotics OF MAN OF ARAN}

As anyone who has taught Man of Aran will know, it can often be difficult to communicate the significance of the film to a present-day audience. At a time when the default mode of the documentary involves fast-paced editing and an intrusive narrative voice, Flaherty's film can seem unbearably ponderous to those acculturated in a more technically-aware filmic milieu. Such issues, however, did not apply when the film was first screened - and this was particularly so in Ireland. As Kevin Rockett (1987: 71) notes, the first Irish screening of Man of Aran in 1934 was a major cultural event. Attendees at the screening included the Prime Minister of the Irish State, Éamon de Valera; various members of his executive and diplomatic corps; Eoin MacNeill, the founder of the Gaelic League; and W.B. Yeats, the Nobel-Prize-winning poet. Few among this constellation of 1930s Irish luminaries were unimpressed with the film, with the general consensus being that Flaherty's work offered an appreciation of 'authentic' Irishness that was untainted by the reductive stereotypes of traditional literature, drama and film. Rockett does well in this connection to retrieve the comments of the nationalist cultural commentator and historian, Dorothy Macardle, who observed that

We have become almost resigned to being traduced in literature, whether under the guise of the comic 'Paddy' of Victorian music halls, or the drunken swindler of some Irish farces or the 'gunman' of more sombre writers today. Not three generations of protesting could do as much to rehabilitate the Irish people in the imaginations of people of other countries as this faithful and beautiful motion picture will do. (Qtd in Rockett et al 1987: 195)

While Macardle's assessment certainly articulates one of the reasons why Man of Aran proved so successful with its contemporary Irish audience, there were also other factors legislating for the film's impact. In particular, a number of scholars have focused on the 
fortuitous match between the ideology outlined in the film and the prevailing political climate in 1930s Ireland. Lance Pettitt, for example, identifies Man of Aran as 'an unwitting endorsement of Fianna Fáil values,' which he identifies as 'self reliance and ascetic frugality' (2000: 80-81). (Under the leadership of Éamon de Valera, Fianna Fáil was the Irish political party most associated with the project of romantic nationalism.) Viewed from this perspective, the film's impact lies less in its reversal of stereotypes than its embodiment of the prevailing 1930s nationalist ideology, which, in Brian Graham's words, held that 'a merger of national identity and economic isolationism would serve both cross-class and sovereign interests' (1997: 91). Here, the idea is that Flaherty's eliding of religious and economic conflicts in the Aran Islands served as a charter for the 'new' Ireland, which Éamonn de Valera's 1943 Radio Address to the Nation envisioned as 'the home of a people who valued material wealth only as a basis for right living, of a people who, satisfied with frugal comfort, devoted their leisure to the things of the spirit.' $^{1}$

However, while all of these analyses of the film offer valuable insights into why it was so successfully received in Ireland, my claim here is that they miss the deeper levels of coding that installed Man of Aran as such an event in Irish cultural life. Specifically, citing the discussion in the previous section, I will argue that these deeper levels of coding reside precisely in the mythic dimensions of Flaherty's film. In essence, this will involve suggesting that the semantic arrangement of Man of Aran made it particularly amenable to the nationalist mythology that informed thinking about the historical emergence of the Irish State. This, I should add, is not to say that Flaherty set out with a nationalist agenda; merely that the form of Man of Aran is compatible with a particular vision of Irish history. In pursuing this claim, I hope the reader will forgive me if I make a brief digression into the field of comparative mythology with a view to making my argument more explicit.

\footnotetext{
${ }^{1}$ In this regard, it is worth parenthetically noting the contrast in political values between Man of Aran and films like Visconti's La terra trema (1948). Though both depict Island-bound, maritime communities struggling for survival, Visconti's exposition, unlike Flaherty's, centres on the impotence of the Islanders in the face of impersonal economic forces. Clearly enough, this difference in emphasis can be attributed to the contrast between Visconti's Marxist commitments and Flaherty's conservative neo-romanticism.
} 
As I have argued at length above, Man of Aran has all the major features of a foundation myth, and to this extent, it should share a number of structural parallels with other myths belonging to this category. In particular, it should resonate with the "theft of fire' myth that is present in almost all cultural traditions for which we have a mythological record. According to Claude Lévi-Strauss, this myth centres on 'the most profoundly meaningful oppositions that it is given to the mind of man to conceive: between the sky and the earth on the level of the physical world, between man and woman on the level of the natural world, and between relations by marriage on the level of the social world' (1981: 624). In narrative terms, these oppositions are articulated through a series of logical entailments - namely, 'there is the sky and there is the earth; between them there can be no conceivable parity; consequently, the presence on earth of that celestial phenomenon, fire is a mystery; since celestial fire is now present here below on the domestic hearth, it must have been brought down from the sky by an expedition that went up from earth to fetch it' (1981: 602). The result, according to Lévi-Strauss, is a body of myths that are structured by the following pattern:

[G]ivers and takers of women are in opposition to each other on the social axis, just as, on the world axis, the earth is opposed to the sky, and the earth in turn to the underworld. So, if primaeval fire is found on the side of the sky, and its necessary receptacle-later to become the oven - on the side of the earth, it follows that the women exchanged through the process of matrimonial alliances, perform, between givers and takers, the same mediatory function as that which, by the inherent logic of the system, they must also assume between fire and earth. (1981: 623)

Implicit in this rather dense formulation is the idea that, in the 'theft of fire' myth (and indeed in myths generally), cosmological and social structures are posited as structurally equivalent, with the consequence that one dimension of human existence can be validly used to articulate another.

Reflecting these ideas back onto Man of Aran, what immediately emerges is that Flaherty's film does not, as might be expected, exhibit this structure. Despite the fact that many of the 'theft of fire' elements are present in the narrative, it is notable that the 
vertical opposition between earth and sky is replaced, in Man of Aran, with a horizontal opposition between earth and sea. In itself, this does not disqualify it as a mythic statement; however, it does raise the question as to what such a cosmological change might signify on the social level. In answering this question, we gain our point of entry into the question of why Man of Aran proved so compatible with the programme of Irish nationalism. Specifically, it is clear that the conversion of a vertical opposition to a horizontal one in Flaherty's film is motivated by the fact that he is depicting an Island society. For obvious geographical reasons, the most salient partitioning of space for an island dweller concerns the division between the island and the mainland. However, in Irish political culture, the horizontal distinction between 'island' and 'mainland' is ideologically loaded; it does not just comprehend a spatial difference, but also expresses the contentious relation between Ireland and imperial Britain in the historical, economic and cultural spheres. One does not have to look far to find instances of this particular political trope. The famous plaque in O'Reilly Street, Havana, for example, celebrates the putative similarities between Ireland and Cuba with the statement 'Two island peoples in the same sea of struggle and hope - Cuba and Ireland.' Similarly, in his 1945 riposte to Churchill's criticisms of Irish neutrality in World War II, de Valera engaged in a carefully phrased equivocation between the notions of 'island' and 'nation' when he stated, 'Mr Churchill is justly proud of his nation's perseverance against heavy odds. But we in this island are still prouder of our people's perseverance for freedom through all the centuries.' Finally, Tom Garvin gestures towards the potent force of the island motif when he notes that 'The image of the Emerald Isle alone and inviolate in the ocean has itself become a cultural symbol, a mute argument for the unity of Ireland and the its necessary separation from Britain' (1994: 84). Thus, there is a clear structural parallel between, on the one hand, the horizontal opposition between earth and sea in Man of Aran, and on the other, the fraught political relationship between Britain and Ireland. In such a scenario, it should be no surprise that the transformation of a celestial opponent to a terrestrial one in Flaherty's film should activate the sensibilities of a nationalist audience.

Nevertheless, static parallels of this kind frequently lack force; for them to gain an exemplary value they need to be paired with dynamic conflicts. Again, we find just such 
a conflict, in coded form, in Man of Aran. In this connection, the reader will remember the discussion of the introductory sequences to the film, where specific mention was made to the attempted abduction of Maggie by the sea. Though seemingly a matter of dramatic detail, viewing this sequence through the lens of Lévi-Strauss's comments reveals a striking parallel with the generic form of the 'theft of fire' myth. Specifically, Lévi-Strauss mentions that a core social opposition in this myth is between wife givers and wife takers - an opposition that is, furthermore, correlated with the distinction between the earth and the sky. In Man of Aran, we see the same social opposition at work, even if its cosmological parallel is transformed. Here, we see the wife taker being equated with the sea and the wife giver being indentified with the Islanders. It requires no great imaginative leap to see how this conflict might resonate with a nationalist perspective on Irish history. Throughout Irish literature and political discourse, there is a persistent figuring of Ireland as a traduced woman, ranging from the aisling figure of Gaelic syllabic poetry to the Cathleen Ni Houlihan of Yeats's eponymous play. Moreover, there is a corresponding representation of Anglo-Irish relations as a form of rape. The nationalist activist and sometime MP for North Clare, O'Gorman Mahon, for example, declared in a parliamentary speech that it was 'blood, rapine and treachery, that produced the Union' (1831: 104). Equally, Vera Kreilkamp (1998: 117) argues there is some evidence that the practice of prima nocta persisted in Ireland up to the nineteenth century; and if this evidence is somewhat anecdotal, there can be no doubt that nationalist propaganda encouraged people to believe it existed. On the other side, there is little need to rehearse the clichés of empire that make imperial Britain a plausible candidate for the role of the hostile sea in Man of Aran. Throughout nineteenth-century British history, the maritime prowess of Britain is advertised as the basis of its world-historical position, with the most mythically loaded statement of this being William Dyce's 1847 fresco, Neptune Resigning to Britannia the Empire of the Sea (figure 8). Thus, through the mechanism of the abduction sequence, Man of Aran succeeds in triggering established interpretive schemas that coordinated the represented agents with political actors. 


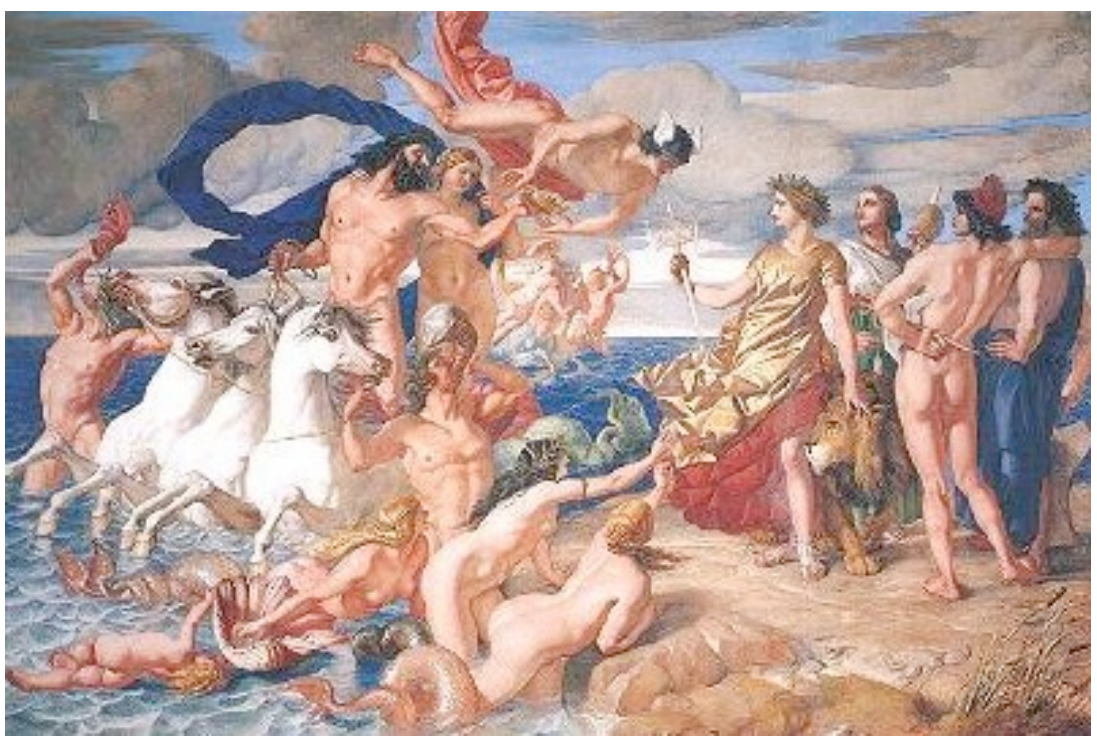

Figure 8: Imperial Britain as Co-Extensive with the Sea

Putting all of this together, what correspondingly emerges is that Man of Aran offered nationalist audiences a set of codings that invited them to correlate the processes of world creation detailed in the film and the 'official' narrative of Ireland's emergence as an independent state. By transforming the mythic opposition between the earth and the sky into one between earth and the sea, the film facilitated the coordination of a cosmological struggle with a political one, and in doing so, affirmed the foundational project of constructing a new nation. Moreover, by referencing the opposition between wife givers and wife takers, Man of Aran also activated an embedded set of cultural codes that figured the fraught history of Ireland and Britain in gendered terms. The result was the establishment of Flaherty's film as an iconic cultural artefact. Indeed, it is likely that it is precisely this congruence between the mythic vision of Man of Aran and the narrative of Irish nationalism that is responsible for the film's seminal role in the establishment of the Irish cinematic tradition.

\section{CONCLUSION}

Now that both the mythic and nationalist dimensions of Man of Aran have been explored, it is possible to return, by way of conclusion, to the motivating issues of the present essay. These, it will be remembered, concern the equivocation between realistic and aesthetic ambitions in the ethnographic documentary. In this connection, it will by now 
be evident that Flaherty's film falls firmly on the aesthetic side of this opposition. For reasons outlined both above and elsewhere, Flaherty's commitment to narrative cinema caused him to persistently subordinate ethnographic reality to the demands of the filmic artefact.

However, while this may seem to deny Man of Aran an ethnographic value, my conclusions here suggest the opposite. As an attempt at cinematic realism, there can be no doubt that Flaherty's film is fatally compromised-but this is only true so long as one takes the director's ambitions as defining the level on which an analysis should be performed. When one views the film instead as an example of contemporary mythmaking, an altogether different picture emerges. From this perspective, Man of Aran has a very high ethnographic value indeed - for after all, it is precisely the aim of ethnography to document mythological beliefs wherever it finds them. That such beliefs should be found in a work of a twentieth-century film-maker rather than in the stories of a pre-technological culture is not the point; for as generations of anthropological scholarship have made clear, the modern situation is no less imbued with mythological ideas than the pre-modern, even if it is reluctant to nominate them as such. Correspondingly, Man of Aran offers a superlative example of a tendency in modern thought that is no less potent for its attempt to deny its origin in the mythic imagination. Certainly, this idea has been mooted before, most notably in Luke Gibbons' (1987) seminal account of primitivism and Romanticism in Irish cinema. Nevertheless, no extant scholarship has recognised the full extent to which Man of Aran actually-as opposed to metaphorically or indirectly - uses the operations of mythic thinking in communicating its meaning.

With all of this in mind, I would like to make the final point that this identification of mythic structures in Man of Aran points to an interesting new possibility for the analysis of Flaherty's work. While it would be invidious to suggest that the analysis of a single film is enough to revise our appreciation of a director's entire oeuvre, the fact remains that the striking semiotic structure of Man of Aran invites comparison with equivalent structures in Flaherty's other documentary films. To be sure, there is no guarantee that films such as Nanook of the North and Moana will evince the same mythic structures that are evident in Man of Aran; but that that does not, on its own, militate against the attempt 
to identify them. If, as I suggest here, the ethnographic documentary is capable of concealing emphatically non-realist modes of representation, then the first imperative of criticism is to expose this. Insofar as the present article has offered one gesture in this direction, it will have achieved its aim as an exposition on how myth, by way of the documentary film, can sometimes masquerade as mimesis.

Acknowledgements: The author would like to thank Leonard Madden, Aidan O'Malley and the anonymous reviewers - all of whom offered many useful suggestions concerning the content of this essay.

\section{References}

de Valera, Éamon (1945), 'Response to Winston Churchill: Radio Address to the Nation,' http://www.rte.ie/laweb/brc/brc_1940s.html. Accessed 10 February 2011. — (1943), 'The Ireland that We Dreamed of: Radio Address to the Nation,' http://www.rte.ie/laweb/11/11_t09b.html. Acessed 10 February 2011.

Eliade, Mircea (1960), Myths, Dreams, and Mysteries, Philip Mairet (trans.), London: Harvill Press.

Gabriël Van der Watt, Jan (2000), Family of the King: Dynamics of Metaphor in the Gospel of John, Leiden: Brill.

Garvin, Tom (1994), 'Nationalism and Separatism in Ireland, 1760-1993: A Comparative Perspective,' In J. Bermanendi, R. Maiz, and X. Nunez (eds.), Nationalism in Europe Past and Future, Santiago: Universidade de Santiago de Compostela, pp. 83-96.

Gibbons, Luke (1987), 'Romanticism, Realism and Irish Cinema,' In Kevin Rockett,

Luke Gibbons and John Hill (eds.), Cinema and Ireland, Syracuse: Syracuse

University Press, pp. 194-203.

Graham, Brian (1997), In Search of Ireland: A Cultural Geography, London: Routledge. Greimas, A.J., (1983), 'Basil Soup or Construction of an Object of Value,' In P. Perron, F. Collins, L. Crist, D. Patte and G. Phillips (ed. and trans.), Paris School Semiotics II - Practice, Toronto: Victoria University, 1983. 
Hugh Gray (1950), 'Robert Flaherty and the Naturalistic Documentary,' Hollywood Quarterly 5, pp. 41-48.

Kimball, Solon T. (1979), 'Man of Aran: 1932-34,' American Anthropologist 79, pp. 749-751.

Kövecses, Zoltán (2000), 'The Scope of Metaphor,' In Antonio Barcelona (ed), Metaphor and Metonymy at the Crossroads: A Cognitive Perspective, Berlin: Mouton de Gruyter, pp. 79-92.

Kreilkamp, Vera (1998), The Anglo-Irish Novel and the Big House, Syracuse: Syracuse University Press.

Lévi-Strauss, Claude (1981), The Naked Man, Jonathan Cape (trans.), Chicago:

University of Chicago Press.

— (1969), The Raw and The Cooked: Introduction to a Science of Mythology, John Weightman and Doreen Weightman (trans.), New York: Harper and Row. MacDougall, David (1992), 'Complicities of Style,' In Peter Ian Crawford and David Turton (eds.), Film as Ethnography, Manchester: Manchester University Press, pp. 90-99.

Mahon, O’Gorman (1831), 'Parliamentary Speech, February $8^{\text {th }} 1831$,' In John Barrow (ed.), The Mirror of Parliament, London: William Clowes, pp. 104.

Malinowski, Bronislaw (1984), 'Myth in Primitive Psychology,' In Magic, Science and Religion and Other Essays, Westport CT: Greenwood.

Messenger, John C. (2001), 'Man of Aran Revisited: An Anthropological Critique,' Visual Anthropology 14, pp. 343-368.

O’Curraidhin, Dara (2010), A Boatload of Wild Irishmen, Nottingham: EM Media.

Pettitt, Lance (2000), Screening Ireland: Film and Television Representation, Manchester: Manchester University Press.

Rockett, Kevin (1987), 'History, Politics and Irish Cinema,' In Kevin Rockett, Luke Gibbons and John Hill Eds.), Cinema and Ireland, Syracuse: Syracuse University Press.

Stoney, George C. (1978), How the Myth was Made, Watertown MA: Documentary Educational Resources. 
Temple-Herr, Cheryl (2003), 'Re-Imagining Man of Aran: The 'First Wave' of Irish Cinema,' The Canadian Journal of Irish Studies 29, pp. 11-16.

Tomaselli, Keyan (1992), 'Myths, Racism and Opportunism: Film and TV Representations of the San,' In Peter Ian Crawford and David Turton (eds), Film as Ethnography, Manchester: Manchester University Press, pp. 205-221.

Visconti, Luchino (1948), La terra trema: Epsidio del mare, Rome: Universalia Film. 